\title{
22
}

\section{Collaborative Research into Contemporary Indigenous Governance}

Linda Ford, Michael Christie, Catherine Bow, Tanyah Nasir,

Michaela Spencer, Matt Campbell, Helen Verran and John Prior

\section{Introduction}

This chapter aims to describe activities of researchers within the Contemporary Indigenous Knowledges and Governance group at the Northern Institute in the changing relations of state governance under conditions imposed by an advanced liberal economy in contemporary Northern Australia and how it intersects with Indigenous governance. This is done by detailing situations where the researchers have found themselves engaged in brokering between Indigenous and modern state (and university) governance practices as they emerge when contemporary Indigenous institutions and contemporary government organisations (GOs) and non-government organisations (NGOs) work together but struggle to conduct their different governance practices together. The chapter details the role of the institute, and of academic work, within this struggle while recognising differences.

While governance issues and practices are of concern to a wide range of research and public engagements in Northern Australia, it is perhaps the issues of governance practices relating to Indigenous communities and organisations that have garnered the most interest and substantial 
amounts of funding. The problematics of Indigenous governance practices arise with the acknowledgement that traditional forms of Indigenous governance are still alive and well in Northern Australia and different to modern practices of nation-state governance in several ways. This chapter describes projects where governments, Indigenous people and researchers are together designing ways of conducting Indigenous and modern governance practices together in productive and sustainable ways.

We begin by defining terms. First, we note that according to the Google program viewer, which tells us about the frequency of word usage in the 'lots' of published English-language books that Google has digitised, the term 'governance' was almost absent up until the 1960s. It seems the term 'government' was the term frequently employed when the relations between states and their peoples and citizens were discussed. However, in the late 1960s the usage of 'government' began to decrease and usage of 'governance' began to increase very rapidly. We take the slow retreat from 'government' and the increase in usage of 'governance' as a significant indicator that something is happening in the ways that states and their peoples relate politically, and in the technical arenas where states manage their populations (Verran \& Christie, 2015). Here, 'government' refers to the mode of governance of and by the Australian state. Nowadays, states often operationalise policies as services provision by NGOs, so the intersecting self-driven governance of Indigenous people and the corporate governance practices of Indigenous NGOs are of interest to us, as are those of GOs.

Consequently, we are interested in governance taken as the overall interplay among multiple 'governances'-odd though that sounds. We are concerned with governance as the Australian state currently understands and practices it in GOs; wider Indigenous governance, inclusive of the corporate governance of a variety of NGOs; and governance as various Indigenous communities understand and practice it in their places. We understand governance as describing relations between 'rules' and 'what is ruled'. 'Rules' of government are laws made by parliaments and regulations devised by civic services, and what governments rule are peoples, citizens or populations and territories. As corporations, NGOs are obliged to make public their rules and what is ruled, and the personnel they employ or whom they retain as volunteers in a formal sense. In contrast, multiple Indigenous people-places (community members, clans and their places) have both unwritten and written rules that are 
variously formalised, and what is ruled are entities we might, in English, call 'people-places'; entities that are indissoluble complexes comprised of elements that are both human and non-human, and material and conceptual—places and their songs, stories and ceremonies.

This chapter presents several case studies. Linda Ford, working with her daughters Chloe and Emily, discusses working with two systems of ethical accountability in 'New Ways for Old Ceremonies'. Michael Christie and Cathy Bow consider some of the challenges of working with texts configured by disparate practices of ownership in 'The Living Archive of Aboriginal Languages'. Linda Ford details the careful work of community engagement in 'Arrakpi Aquaculture' on Goulburn Island. Tanyah Nasir and Michaela Spencer reflect on some of the potential effects of governance work in 'Tiwi Community Governance', and Matt Campbell considers questions around the production of evidence in Indigenous research in 'Tangentyere Research Hub'.

Five projects are briefly described through these case studies. Being careful to respect the profound differences between these projects, we nevertheless suggest that they might be thought of as falling into two groups. One group is concerned with what we might call 'objects of governance'-'New Ways for Old Ceremonies', concerned with archival records of ceremonies, songs, performances, rituals and stories, assembled largely in past anthropological research; 'The Living Archive of Aboriginal Languages', concerned with written texts and their digitised web-based doppelgangers; and 'Arrakpi Aquaculture', concerned with wild harvest of fisheries products. The second group is concerned with organisational processes-'Tiwi Community Governance' and 'Tangentyere Research Hub'. In describing these projects, this chapter shows how we, as researchers, are embedded in the 'action', the 'doing' to recognise who and what the other participants are, in being and recognising that their interests differ from ours, as researchers. Being explicit about the knowledge drawn on and the governance practices of our research is the way we as researchers participate in good faith. 


\title{
New Ways for Old Ceremonies: An Archival Research Project
}

\author{
Linda Ford
}

The New Ways for Old Ceremonies: An Archival Research Project aims to develop and implement suitable frameworks for the preservation, interpretation and dissemination of recordings of ceremonial performances of the Mak Mak Marranunggu people of the Northern Territory (NT). The focus is a body of recordings by early anthropologists and missionaries (from 1824-2009) of the final mortuary ceremonies performed. The ceremonial performance is a key process for integrating Indigenous knowledge from many different domains - a socially powerful site of exchange, transmission and transformation of relationship to country, kin and identity (Ford et al., 2014).

As a Mak Mak Marranunggu person, this research has involved me working with the ceremonial knowledge of my own people and places. We call ourselves Tyikim. During my PhD, I worked with my mother, Ngulilkang Nancy Daiyi, and other elders from my community to find ways to bring my Tyikim knowledge traditions into the university classroom (Ford, 2010). Now, I seek to work the other way and bring the knowledge and technologies of the university to help my daughters, Chloe and Emily, and extended family and related clan groups keep our traditional ceremonies alive.

This project is just beginning, and it will take a long time to organise and finalise all the complex negotiations required for this work. However, I have already encountered a dislocation between the forms of ethical accountability recognised by the university and the practices of ethical accountability observed and undertaken by my people. I am sometimes caught in the middle. As we look through old video footage, I need to set up systems that allow for negotiations around who may view the film, and how it may continued to be used and exhibited in the future. In doing this work, I am guided by my elders and act on their instruction. I am accountable to their directives and the way they guide me to observe proper protocols for managing cultural objects in the work we are doing together. To do this carefully and well, I depend on the good faith and goodwill of my elders who are supporting me in the project. 
Aware of my accountability in these terms, I felt confident that I would be able to carry out this research with the support of my colleagues and family members. However, a letter from the university ethics committee asked me to account for my research and its impacts in a rather different way, challenging me on several issues that were very difficult for me to address. They wanted to know if the outcomes of the research might 'consolidate and strengthen' the status of my family compared to others and whether this 'might cause disharmony or offence' to other families. The ethics committee also wanted to know how my Elders would be involved, how their involvement might differ from a 'consultation and negotiation processes' and how I would make that clear in a 'plain language statement'.

It was immediately clear to me that the ethics committee did not really understand how I was being guided by protocols of ceremony, and so did not really understand how the project was going to be negotiated. Or, if they did understand, perhaps they were constrained by their own protocols, rules and regulations, which saw research as dealing with the standard research subjects of a university-anonymous subjects, who are not induced to participate or rewarded, and who are subjects of the research, not researchers.

When working with my own people, I do not need to account for my work in these ways. However, when also doing this work with and for the university, I do need to justify myself to the ethics committee and be completely honest with them. I had to discuss the questions with my elders and be quite upfront. Yes, the status of my family may be consolidated and strengthened through this project, but the 'family' that is represented in this ceremonial context is spread through a large geographical area including the Batchelor, Darwin, Belyuen, Wagait and Daly regions, and includes many people and multiple clans and language groups. It is fully expected that other ceremonial groups, such as the Wangga, Lirrga and Djanba, will be very interested in my work and inspired to undertake a search for archived materials that might help them with similar work. My family would be very happy to support them with this.

But what is important is continuing to listen to the elders to express their knowledge within our work together. It is for them to tell me how to do this research. The ethics committee may have been a little surprised by 
my answers, but they have accepted them and, so far, I have been able to work Tyikim governance and university governance together without any trouble.

\section{The Living Archive of Aboriginal Languages}

\section{Michael Christie and Catherine Bow}

In the 'Living Archive of Aboriginal Languages project, we are involved in designing and developing an archive of rare texts in over 50 endangered Indigenous languages of the NT. ${ }^{1}$ Between 1974 and 2000, thousands of books were produced in remote communities in an era of significant government support for vernacular education and the training of Indigenous teachers and language workers for bilingual education. We now find ourselves in an era when bilingual education is no longer supported by the Australian state, and the use of English in teaching and literacy is official policy, resulting in disuse and endangerment of these materials of cultural and linguistic importance.

Funding was obtained to work in collaboration with other tertiary institutions and government and non-government departments to 'rescue' the literature and to catalogue, digitise and configure it using web technologies. The creation of a website for the use of the language owners and authorities (Christie 1993; Christie \& Perrett, 1996), and new generations, as well as for classroom teachers and students, academic teaching and research nationally and globally, required careful consideration of the needs of different users and different requirements of the technology (Bow et al., 2014).

We recognise that the items that constitute this archive are in a strong sense owned by the communities in which they were produced; that ownership lies with those whose languages and stories are mobilised in the texts. Yet at the same time, in being produced as written texts generated in the work of state-funded literature production centres, the items in the archive are equally in some ways owned by the governments of the Australian state. Thus, the items are subject to disparate traditions of governance, which, in constituting the archive, we as researchers must negotiate in good faith

1 See laal.cdu.edu.au/. 
(Christie et al., 2014; Bow \& Hepworth, 2019). We do not have the space here to detail how and where those disparate traditions of governance clash in some places and mesh in others when it comes to the day-to-day practices of constituting the archive.

The conventional academic view of the academic researcher is that they should be removed, impartial and somehow 'all seeing', so that the knowledge claims they might make about, say, the worth or otherwise of such an electronic archive, and how it might be subject to a transparent regime of good governance, might be epistemically valid. We doubt that such an idealised position was ever achievable, but irrespective, it is certainly not a position we aspire to. So, from what sort of a position might we generate valid and useful generalisations about such an archive and an appropriate governance regime? And how do the technical requirements fit into this?

This work involves careful ongoing balancing between the centralised top-down configurations for robust coding and sustainable and extensible development (as described in Bow et al., 2014), and the dispersed localised reappropriation and enrichment of documents on country under the authority and for the benefit of their owners. The negotiation of permission and copyright issues also requires careful consideration of both Indigenous and Western concepts of ownership and access to knowledge. This work finds us re-examining our role as experts and researchers in the changing worlds of government policies, education, technology and remote community sustainability. And it opens more fundamental metaphysical questions around the nature of language itself and its relation to country, people, identity and technology. Each new challenge needs to be carefully thought through, not least with respect to what good faith participation requires.

\section{Arrakpi Aquaculture}

\section{Linda Ford}

While working on the New Ways for Old Ceremonies: An Archival Research Project, I was also invited to participate in a project developing an aquaculture industry in the Indigenous community at Warruwi on Goulburn Island, NT. It was part of a wider project called 'Identifying the key social and economic factors for successful engagement in aquaculture ventures by Indigenous communities'. 
The original project came from the Fisheries Research and Development Corporation (FRDC), as part of an effort to build sustainable aquaculture in remote communities. Its focus was around identifying key factors for success in Indigenous businesses and the development of a fisheries-based community development program.

When I first became involved in this project in 2013, its 'community engagement' aspect had been running for a long time but had only minimal success. Work had been continuing for many years, but while it had, in the words of one of the scientists, 'ticked all the boxes', the project was still not progressing. Nobody seemed to be interested.

The FRDC milestone identified the senior Arrakpi women from the community to work together under the auspice of the Yagbani Aboriginal Corporation to make some decisions and support the project. The women were busy, they were from quite different families and clan groups who did not seem interested in the project and the project was not their idea in the first place. This might have been why engagement had minimal uptake and progress was slow. The Yagbani Aboriginal Corporation, registered in 2012, was up and operating, and the Arrakpi directors were familiarising themselves with their roles and responsibilities as board members.

I have a few distant kinship relationships at Warruwi, so I agreed to accompany them and seek authorisation from the Traditional Owners of the aquaculture area to join the research project team. They were happy to invite me to be a researcher on the aquaculture enterprise development project because I was connected to them through both my Indigenous and research backgrounds. My first priority was identifying and locating the right people to talk to, to see if they would be happy for me to join the research team. Gradually, I began to meet a few more women, many of whom I could trace some connection to. We had several meetings and discussions. The women were mostly interested in food for the community's children and elders, so it was through focusing on the traditions associated with seafood that we finally began to work together and develop a collective interest in how this aquaculture project, if it was going to work, should be negotiated and implemented.

It was through the stories that connected them to each other, the sea and the new generation that the women elders became engaged. One day, we had a breakthrough. I spotted leaning on the wall of the Warruwi school staff room an old chart that had been produced by senior women and men 
back in the days of bilingual education. The chart had names and a few pictures of dozens of sea (and a few land) animals good for eating at different times of the year. The names were arranged into a circle, as a seasonal calendar with the seasons, months and prevailing winds all in the local language, Maung. It promoted much discussion and brought the women together because it was a sign, of senior women who had gone before them and whose knowledge and connections were so valuable, and for the new generation of young children. We used some of our funding to make the old drawing into a new poster, and then into a digital version, which eventually ended up on the Warruwi Fisheries and Aquaculture Knowledge Partnership Project website. ${ }^{2}$ It was through this new work, this object we were gradually creating together, that community engagement that was meaningful to both parties (and that was supported by an emerging new Indigenous enterprise) began to be conducted.

\section{'Tiwi Community Governance'}

\section{Tanyah Nasir and Michaela Spencer}

In this project, we (Nasir and Spencer) were involved in developing governance and leadership capacities in the community of Wurrumiyanga. Amid continually shifting responsibilities of local, regional and state governments, and as new forms of enterprise development were springing up in the Tiwi Islands, we worked collaboratively with people in the community, telling stories and learning together about governance. We talked about how governance work was being done and explored ways that young people might be supported to confidently participate in these processes in the future.

This work was funded as part of an NT Government project on governance and leadership in remote Indigenous communities. It was born out of a recognition that amid the proliferation of government and corporate governance training practices in remote Indigenous communities, there was very little work being conducted on the ground, taking account of how existing and new governance structures were being negotiated and engaged with by local people. Working under the guidance of elders, and led by two Indigenous facilitators, we ran a series of workshops focused

2 yagbaniac14.wix.com/aquacultureknowledgeproject\#!warruwi-projects/c10d6. The Yagbani Aboriginal Corporation manages this site. 
on 'problems of the moment' arising in the community, moving between Tiwi and English languages and working through Tiwi skin groups and family hierarchies, while being explicit about the forms of university administration and protocols that we were required to follow.

Many of the Tiwi people attending the workshops knew, or were in some way related to, the facilitators. They felt comfortable to raise and discuss issues that were important to them, but that might otherwise go unarticulated. We also worked closely with a local elder, Bonaventure Timaepatua, who guided us regarding who were the right people for us to invite and where our discussions should be focused. Identifying that there is often a disconnect between governance and leadership work being done in the community, and governance and leadership work being conducted in council offices and board meetings, we often used this as a place to work collaboratively with Tiwi people while supporting them to feel confident in engaging multiple sets of governance practices, while also continuing to work with and within the community.

However, in doing this work we were frequently reminded that our own practical assumptions were themselves artefacts of earlier activitiestemporary working settlements that had enabled Tiwi governance and Western governance to mingle and coexist. Working in groups to tell stories about how 'Tiwi Way' was involved in the work of councils, boards, schools and tiers of government, we began by talking about the four Tiwi skin groups-Warnarringuwi, Miyartuwi, Takaringuwi and Mantimapila. But very soon, we found ourselves delving into the recent past of Tiwi governance relations. As it turned out, while there actually are 16 subgroups it had become common to work only with the main four. This simplification was an artefact of needing to organise meetings and arrange for equal representation of the four groups within council and other meetings. It was, in part, a shift and a solidification brought about through the requirements and opportunities of representational governance.

Recognising that our government-specified brief is to participate and intervene in shaping the ways in which community governance is done, we began to see ourselves as also working to craft partial and temporary settlements, working compromises and moments of collaboration that produce particular separations and connections. ${ }^{3}$ Wary of these becoming solidified and the contingency of their creation lost, we hesitated before

3 For further explanation of the methods involved, see www.cdu.edu.au/centres/groundup/. 
writing definitive accounts or reports of our work and the outcomes it has achieved. Instead, we were pushed back towards offering accounts of our practices that retained these difficulties and governance work in communities that supported capacities to produce new and different temporary settlements into the future.

\section{Tangentyere Research Hub}

\section{Matt Campbell}

The Tangentyere Council is the governing body for 17 Aboriginal 'Town Camps' in the Alice Springs area. It runs the Tangentyere Research Hub as one of its key services, and I, as the coordinator of this research unit, work both with Indigenous researchers in the Alice Springs Town Camps and (at times) with Charles Darwin University. The Research Hub was established within the Tangentyere Council to give Town Camp residents a chance to provide feedback for the evaluation of the first Alice Springs liquor trials, introduced by the NT Government in 2002 as a strategy for addressing alcohol-related problems in Alice Springs. Since then, the Tangentyere Research Hub has grown and conducted a wide range of projects. In 2020, it continues to plan, undertake and report on research on issues of concern to Town Camp residents. Aside from myself, all employees of the Research Hub are Indigenous people with strong connections to the Town Camps and Arrernte language and culture.

In recent times, the Arrernte researchers have become concerned that the research they are asked to undertake has often been framed and specified according to Western ways of collecting and producing evidence. They have spoken of themselves as simply 'clip-boards for hire', required only to collect data without the opportunity to undertake the sorts of collaborations between funding bodies, governments and people on the ground that reflect their own traditional agreement-making practices. They note that this may produce changed understandings and practices that could contribute to what constitutes 'good' research in this context through engagements with governments, universities, NGOs and Town Camp residents.

In seeking to make a difference, we are interested in how our research is understood within the Town Camps and by those who provide funding to undertake projects. To achieve this, we are exploring the notion of 
'accountability' as we believe this will help us to make visible the criteria that people use for evaluating our work (Campbell et al., 2014). Looking at accountability will help us and others to understand the ends to which different parties aspire through our research work.

Several issues have emerged, particularly in relation to the conduct of research work and its outcomes. On the one hand, paying attention to accountability helps us to do meaningful and productive work because we are consciously working to ensure that our research delivers benefit to Town Camp residents. Our ability to do this is increased because all the researchers are known and trusted and know how to work respectfully in the Town Camp context. In addition, every researcher is also part of the complex governance of the Town Camps; they are part of families, thus they are aligned in ways determined not only by themselves but by the community, meaning that they could not do 'arms-length' research even if they wanted to. Finally, we are contracted by various GOs and NGOs to undertake research through the Tangentyere Council. Working to understand these multiple and complex accountabilities has the potential to change the way research is done and alters the way accountability might be understood.

We are exploring how we might conceptualise and make visible our accountability story so that we might involve a diverse range of Town Camp residents (and other participants) in helping us to do work that works for them. In this way, we are seeking to better understand how we might make the complex politics of Town Camps and their governance systems visible, both internally, so that it can be more effectively engaged with, and externally, so that agencies we partner with can understand what we are doing and why taking our accountabilities seriously is the right and proper thing to do.

\section{Conclusion}

Emergent in our descriptions is a figure of an academic researcher involved in a wide range of projects in various remote places, drawing on a diverse repertoire of personal expertise and relationships. Sometimes characterising this work as 'ground up', we have previously recognised ourselves as working with and within both traditions of Western European and Aboriginal knowledge and governance practices, face to face in very local contexts, where both traditions must adapt. This work entails starting with and accepting 
difference and negotiating ways of making connections. It involves resisting the usual role that academics are cast in, as 'removed judging observers', and instead seeing ourselves as particular sorts of participants in the collective action of generating sustainable and transparent governance practices when cooperating across linguistic, cultural and epistemic boundaries (Addelson, 2002). Located within the Northern Institute, we see ourselves as having and changing roles, and those roles as themselves emerging from collective action of those struggling to coexist due to differences in knowledge and governance practices.

However, these accounts also show that we are now increasingly finding our role to be one of not just brokering and translating across differences between differing knowledge and governance traditions, but of also grappling with how differences in knowledge and governance traditions might remain visible as something we are all accountable to, within the practices and processes of new forms of governance. Working within this new and multiply implicated positioning, while visibly holding tensions associated with difference, we have begun to explore possibilities for making connections that have a chance of generating futures that do not merely reproduce pasts.

\section{References}

Addelson, K. P. (2002). The emergence of the fetus. In C. L. Mui \& J. S. Murphy (Eds), Gender struggles: Practical approaches to contemporary feminism (pp. 118136). New York, NY: Rowman \& Littlefield.

Bow, C. \& Hepworth, P. (2019). Observing and respecting diverse knowledge traditions in a digital archive of Indigenous language materials. Journal of Copyright in Education and Librarianship, 3(1), 1-36. doi.org/10.17161/jcel. v3i1.7485

Bow, C., Christie, M. \& Devlin, B. (2014). Developing a living archive of Aboriginal languages. Language Documentation \& Conservation, 8, 345-360. hdl.handle.net/10125/24612

Campbell, M., Foster, D. \& Davis, V. (2014). Looking back, moving forward: The place of evaluation at the Tangentyere Council Research Hub. Learning Communities Journal, 14, 144-153. doi.org/10.18793/LCJ2014.14.10

Christie, M. J. (1993, June). Yolngu linguistics. Ngoonjook, (8), 58-77. 
Christie, M., Devlin, B. \& Bow. C. (2014, October). The birth of the living archive: An emerging archive of Australian Aboriginal languages and literature. Archifacts, 48-63.

Christie, M. \& Perrett, B. (1996). Negotiating resources: Language, knowledge and the search for 'Secret English' in northeast Arnhem Land. In R. Howitt, R. Connell \& P. Hirsch (Eds), Resources, nations and Indigenous peoples (pp. 57-65). Melbourne, Vic.: Oxford University Press.

Ford, P. L. (2010). Aboriginal knowledge, narratives \& country: marri kunkimba putj putj marrideyan. Brisbane, Qld: Post Pressed.

Ford, P. L., Barwick, L. \& Marett, A. (2014). Collaborative Ethnomusicology: Caring about ceremony: Indigenous knowledge across boundaries of time, space and society. In K. Barney (Ed.), Collaborative ethnomusicology: New approaches to music research between Indigenous and non-Indigenous Australians. Melbourne, Vic.: Lyrebird Press.

Miller, P. \& Rose, N. (1990). Governing the present. Cambridge, England: Polity.

Verran, H. \& Christie, M. (2015, March). Editorial. Learning Communities Journal, (15), 4-7. 
This text is taken from Leading from the North: Rethinking Northern Australia Development, edited by Ruth Wallace, Sharon Harwood, Rolf Gerritsen, Bruce Prideaux, Tom Brewer, Linda Rosenman and Allan Dale, published 2021 by ANU Press, The Australian National University, Canberra, Australia. 